\title{
Divisão fisiográfica da bacia do rio Buranhém como subsídio para o planejamento e gestão dos recursos hídricos
}

Gabriela Mateus de Fontes Silva ${ }^{1^{*}}$ (D), Elfany Reis do Nascimento Lopes ${ }^{2}$ (D), Fabrício Berton Zanchi $^{2}$ (D), João Batista Lopes da Silva ${ }^{3}$

\footnotetext{
${ }^{1}$ Instituto Federal da Bahia, Campus Vitória da Conquista, Av. Sérgio Vieira de Mello, 3150 - Zabelê, Vitória da Conquista - BA, 45078-300. Centro de Formação em Ciências Ambientais da Universidade Federal do Sul da Bahia UFSB, Rodovia BR-367 Km 10, Zona Rural, Porto Seguro - BA, 45810000.

${ }^{2}$ Centro de Formação em Ciências Ambientais - CAM/UFSB, Campus Sosígenes Costa, Centro de Formação em Ciências Ambientais da Universidade Federal do Sul da Bahia - UFSB, Rodovia BR-367 Km 10, Zona Rural, Porto Seguro - BA, 45810000.

${ }^{3}$ Instituto de Humanidades, Artes e Ciências - IHAC/UFBS, Campus Paulo Freire, Praça Joana Angélica, 58 - São José, Teixeira de Freitas - BA, 45988-058

* Autor para correspondência: gabrielamfontes@yahoo.com.br
}

Recebido em 14 de abril de 2020.

Aceito em 12 de dezembro de 2020.

Publicado em 31 de dezembro de 2020.

Resumo - A análise fisiográfica das bacias hidrográficas e a sua caracterização são ferramentas para a gestão destes territórios. O estudo objetivou avaliar estas características para a bacia hidrográfica do rio Buranhém, no Sul da Bahia, ponderando-as como fatores de impacto ambiental de modo a compartimentalizar a bacia. Realizou-se o processamento do Modelo Digital de Elevação (MDE) e da cobertura do solo cedidos pelo Fórum Florestal do Extremo Sul da Bahia utilizando o software QGIS 2.18. Também foram analisados os dados hidrometeorológicos, de vazão e precipitação disponíveis na rede nacional (Hidroweb/ANA). Os dados foram avaliados por sub-bacia, atribuindo pesos de acordo com o efeito de transmissibilidade superficial da água e concentração do deflúvio, descritos na literatura. Observou-se que bacias alongadas, com baixa cobertura vegetal e relevo acentuado podem ter tendência a inundações devido ao escoamento superficial favorecido, o que resulta em riscos de erosão, perda de solo, assoreamento, comprometimento da qualidade da água e baixa disponibilidade de água ao longo do tempo. A fisiografia se deu com a compartimentalização em quatro sub-bacias de contribuição de acordo com o potencial de impacto nos recursos hídricos, servindo de apoio para a gestão da bacia como território heterogêneo com diferentes tendências naturais e antrópicas.

Palavras-chave: Geoprocessamento; Sul da Bahia; Regionalização; Desmatamento.

\section{Physiographic division of the Buranhém river basin as a subsidy for water resources planning and management}

Abstract - The physical characterization of any watershed is a tool for the management of these territories. This study aimed to evaluate these characteristics for the hydrographic basin of the Buranhém river, in south of Bahia, considering them as factors of environmental impact in order to compartmentalize the basin. The Digital Elevation Model (DEM) and the soil cover provided by 
the Forestry Forum of the Extreme South of Bahia were processed using the QGIS 2.18 software. Hydrometeorological, flow and precipitation data available on the national network (Hidroweb / ANA) were also analyzed. The data were evaluated by sub-basin, assigning weights according to the effect of surface water transmissibility and defluvium concentration, described in the literature. It was observed that elongated basins, with low vegetation cover and accentuated relief may show a tendency to flood due to the favored surface runoff, which results in risks of erosion, loss of soil, silting, compromised water quality and low availability of water to the surrounding area. The analysis resulted in the compartmentalization into four contributing sub-basins according to the potential impact on water resources, being a tool to support the planning of the basin as a heterogeneous territory with different natural and man-made tendencies.

Keywords: Geoprocessing; South of the Bahia; Regionalization; Deforestation.

\section{División fisiográfica de la cuenca del río Buranhém como subsidio para la planificación y gestión de recursos hídricos}

Resumen - El análisis fisiográfico y la caracterización de las cuencas hidrográficas son herramientas para el manejo de estos territorios. El estudio tuvo como objetivo evaluar estas características para la cuenca hidrográfica del río Buranhém, en el sur de Bahía, considerándolas como factores de impacto ambiental para compartimentar la cuenca. El Modelo de Elevación Digital (MED) y la cobertura del suelo proporcionada por el Foro Forestal del Extremo Sur de Bahía se procesaron utilizando el software QGIS 2.18. También se analizaron los datos hidrometeorológicos, de flujo y precipitación disponibles en la red nacional (Hidroweb / ANA). Los datos fueron evaluados por subcuenca, asignando coeficientes de acuerdo con el efecto de la transmisibilidad del agua superficial y la concentración de la escorrentía, descritos en la literatura. Se observó que las cuencas alargadas, con baja cobertura vegetal y relieve acentuado pueden tender a inundaciones debido al escurrimiento superficial favorecido, lo que resulta en riesgos de erosión, pérdida de suelo, sedimentación, calidad comprometida del agua y poca disponibilidad de agua a lo largo del tiempo. La fisiografía se ha dado con la compartimentación en cuatro subcuencas de contribución según el impacto potencial sobre los recursos hídricos, siendo un subsidio para el manejo de la cuenca como un territorio heterogéneo con diferentes tendencias naturales y antrópicas.

Palabras clave: Geoprocesamiento; Sur de Bahía; Regionalización; Deforestación.

\section{Introdução}

As bacias hidrográficas possuem processos que envolvem em sua dinâmica, resultados da interação entre as características físicas, naturais e antrópicas, que incluem a interferência do uso e ocupação do solo, barramento e captação de água superficial ou subterrânea e suas possíveis alterações no regime hidrológico (Rocha 2010; Santos et al. 2010).

O rio Buranhém nasce no leste de Minas Gerais e deságua no oceano Atlântico através de uma foz do tipo estuário, em Porto Seguro, Bahia. A delimitação física de sua bacia hidrográfica possui maior porção na região Sul baiana, no território de identidade conhecido como Costa do Descobrimento. A região é reconhecida por sua megadiversidade e por estar inserida no Corredor Central da Mata Atlântica, um hotspot de biodiversidade do planeta (MMA, 2006). Historicamente, a região da Costa do Descobrimento, onde o rio Buranhém está localizado, é reconhecida pelo 
desmatamento da Mata Atlântica, que tem convertido áreas naturais para pastagens e silvicultura, agricultura, e expansão urbana desordenada.

A legislação brasileira deixa explícita a importância da cobertura vegetal e a necessidade da gestão e planejamento do uso do solo em consonância com a gestão dos recursos hídricos. Neste sentido, o planejamento ambiental colabora para as bacias hidrográficas como unidades básicas de gestão dos recursos hídricos e de uso e ocupação do território, articulada com uma diversificada política de regularização de atividades considerando o Código Florestal, que define as Áreas de Preservação Permanente, e da Política Nacional dos Recursos Hídricos (PNRH) (BRASIL 2007; 2012).

Por serem definidas por limites físicos, as bacias hidrográficas extrapolam as divisões políticas e administrativas, revelando uma heterogeneidade de características que podem influenciar no regime hídrico dos rios e seus afluentes. Esses rios interconectam territórios e promovem a interação de seus elementos físicos, biológicos, sociais e políticos (Schussel e Nascimento Neto 2015). O diagnóstico ambiental é a primeira etapa para estabelecer planejamento nessas áreas e a efetiva gestão dos recursos hídricos envolve atuação interdisciplinar (Tucci e Mendes 2006).

No entanto, outros fatores relevantes precisam ser interpretados numa bacia, como: o manejo do solo em atividades agrícolas, aumento do escoamento superficial, riscos de erosão, perda de solo e uma redução da alimentação do aquífero (Tucci 2002). Esses fatores atuam com diferentes impactos nas áreas hídricas, revelando a importância de estudos morfométricos que avaliem a capacidade morfoestrutural e o comportamento hidrológico da bacia hidrográfica (Villela e Mattos, 1975; Tucci e Mendes, 2006). Essa avaliação pode se dar com a utilização de parâmetros ambientais, auxiliando a tomada de decisões na gestão e preservação dos recursos hídricos. Para isso, variáveis como pedologia, cobertura vegetal e climatologia são comuns nesses estudos. Contudo, a análise morfométrica, pode agregar conhecimento em relação à dinâmica hídrica da bacia hidrográfica e configurar-se como uma metodologia simples e econômica para caracterizar a bacia hidrologicamente e fisiograficamente, indicando sua vulnerabilidade a inundações, tempo de concentração de água, forma e direcionamento de fluxo de ordens de corpos d'água (Kabite e Gessesse 2018).

Análises com essa perspectiva são úteis para o delineamento de estudos de campo e planejamento de ações estratégicas para manutenção da qualidade e quantidade de recursos hídricos e o potencial de inundações e de erosão em determinadas regiões de uma bacia hidrográfica (Sarkar et al. 2020). De forma similar, a adoção da divisão de uma bacia hidrográfica em sub-bacias, permite ranquear os fatores que potencializam a infiltração ou o escoamento, priorizar as ações a serem adotadas para a conservação e recarga dos recursos hídricos (Mundetia et al. 2018).

A bacia hidrográfica do rio Buranhém encontra-se em uma região de grande diversidade ecológica, mas que possui muitas áreas intensamente antropizadas, além disso, devido à sua extensão, apresenta uma grande heterogeneidade de características. Considerando a perspectiva de compartimentalização, a divisão fisiográfica facilita a sua gestão ambiental e territorial, pois permite analisar individualmente e determinar cenários futuros (Almeida et al. 2018). Pela importância da bacia hidrográfica do ponto de vista da conservação dos recursos hídricos, da socioeconomia e da biodiversidade, objetivou-se realizar a divisão fisiográfica da bacia hidrográfica do rio Buranhém, diante de suas tendências naturais e possíveis impactos relacionados com a forma, o relevo e os usos do solo predominantes, visando a divisão em regiões homogêneas de gestão hídrica. 


\section{Material e Métodos}

\section{Área de estudo}

O rio Buranhém, nasce no leste de Minas Gerais, no município de Santo Antônio do Jacinto, passando pelos municípios baianos de Guaratinga, Eunápolis e Porto Seguro, e é importante para o desenvolvimento econômico e social da região. Através do Decreto Estadual no 14.244 de 18 de dezembro de 2012, foi criado o Comitê da Bacia Hidrográfica dos Rios Frades, Buranhém e Santo Antônio (CBHFRABS), sem plano de gestão até a presente data.

A área de estudo (Figura 1) está localizada entre as coordenadas geográficas $16^{\circ} 15^{\prime}$ e $16^{\circ} 45^{\prime}$ Sul e $39^{\circ}$ e $40,5^{\circ}$ Oeste, limitada ao Norte com a bacia do rio João de Tiba, e ao Sul com a bacia do rio dos Frades que também deságuam em Porto Seguro - Bahia, no interior, faz limite com as bacias dos rios Jequitinhonha, ao Norte e Jucuruçu, ao Sul. Segundo a ottocodificação, realizada pela ANA, o código da bacia é 77514 e o curso principal é de sexta ordem.

Figura 1. Mapa de Localização da Bacia Hidrográfica do rio Buranhém e regiões de planejamento hídrico.
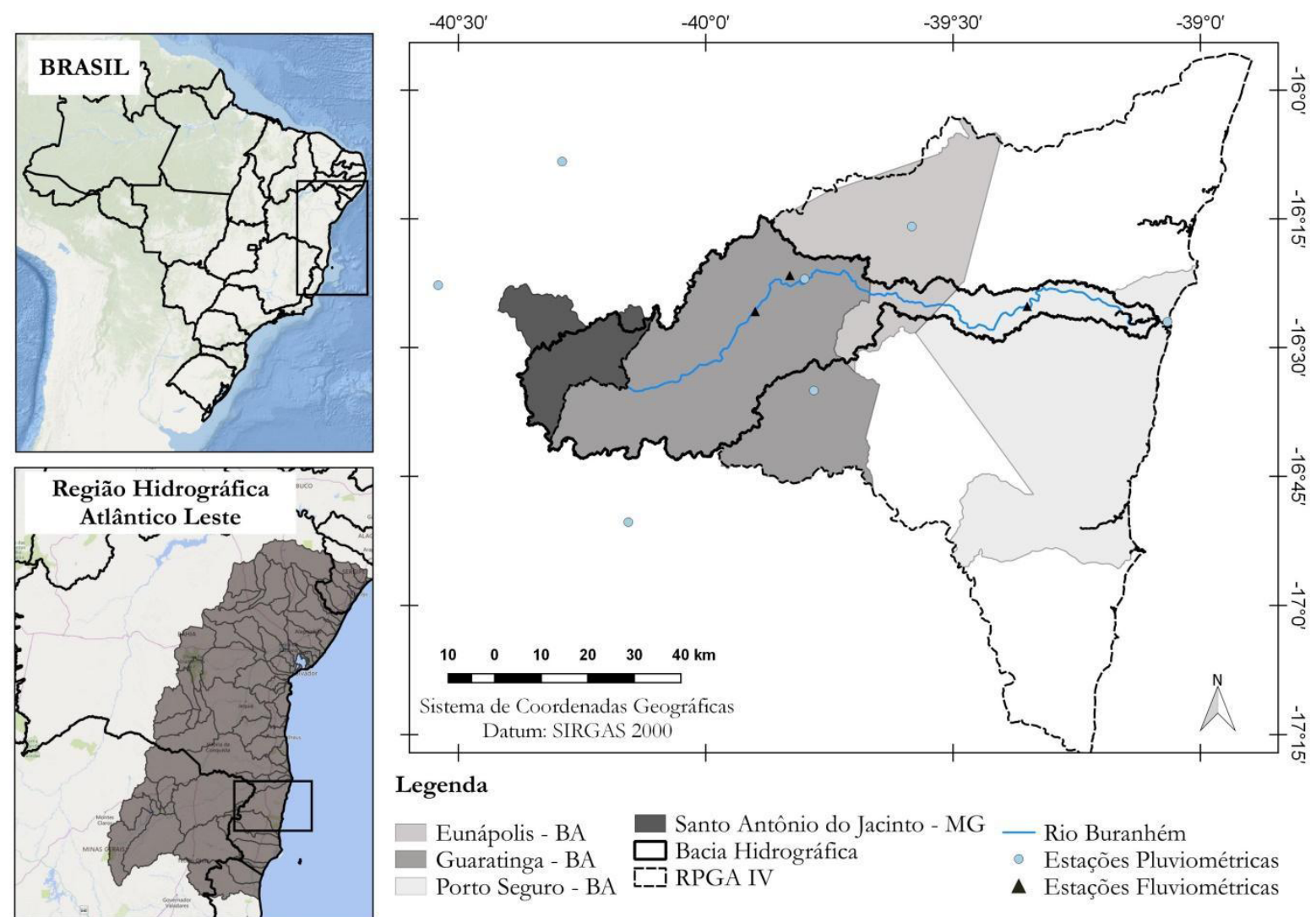

Fonte: Autoria própria (2020); Dados vetoriais: INDE (2016).

Delimitação da bacia e obtenção dos parâmetros morfométricos

A bacia foi delimitada através do Modelo Digital de Elevação (MDE), com resolução horizontal de $30 \mathrm{~m}$ e vertical de $1 \mathrm{~m}$ originado do Shuttle Radar Topography Mission (SRTM), disponível 
no Banco de Dados Geomorfométricos do Brasil - Projeto TOPODATA do Instituto Nacional de Pesquisas Espaciais (INPE).

O MDE foi processado e analisado no software QGIS 2.18 com interface para o Geographic Resources Analysis Support System (GRASS). Procedeu-se a correção de células vazias e remoções de depressões espúrias, para assim poder gerar o Modelo Digital de Elevação Hidrologicamente Consistente (MDEHC), que permite a simulação do escoamento superficial contínuo, gerando a drenagem numérica, a direção de fluxo, fluxo acumulado e o exutório da área de interesse, sendo ele o ponto mais próximo à foz do rio Buranhém. Para definição do exutório avalia-se de forma exploratória a drenagem numérica gerada pelo MDEHC, selecionando a coordenada do ponto mais a jusante do curso d'água principal. O MDEHC também foi utilizado para gerar os dados de hipsometria e declividade da bacia hidrográfica.

Foram calculadas as variáveis morfométricas para caracterizar a bacia hidrográfica, avaliada através dos índices, descritos no Quadro 1.

Quadro 1. Parâmetros e Índices Morfométricos para bacias hidrográficas.

\begin{tabular}{|c|c|c|}
\hline PARÂMETRO & REFERÊNCIA & SIGNIFICADO \\
\hline Área (A) & Tucci (1993) & Área de captação e drenagem da água pluvial. \\
\hline Perímetro (P) & Tucci (1993) & Contorno da área de drenagem. \\
\hline Comprimento Axial (L) & Tucci (1993) & Distância do exutório ao ponto mais longínquo da área. \\
\hline Amplitude Altimétrica $(\mathrm{H})$ & Tucci (1993) & Diferença entre a altitude máxima e mínima \\
\hline $\begin{array}{c}\text { Comprimento dos Canais } \\
\text { (Lt) }\end{array}$ & Tucci (1993) & Soma dos comprimentos de todos os canais \\
\hline $\begin{array}{l}\text { Comprimento do canal } \\
\text { principal (Lc) }\end{array}$ & Tucci (1993) & Distância percorrida pela água no curso principal. \\
\hline $\begin{array}{l}\text { Coeficiente de } \\
\text { compacidade } \\
\mathrm{Kc}=0,28 \frac{P}{\sqrt{A}}\end{array}$ & Tucci (1993) & $\begin{array}{l}\text { Varia de } 1 \text { ao infinito, sendo que próximo de } 1 \text {, indica uma bacia } \\
\text { mais circular e mais sujeita a enchentes, e enquanto maior a } \\
\text { compacidade mais irregular é a bacia. }\end{array}$ \\
\hline $\begin{array}{l}\text { Îndice de Circularidade } \\
\qquad \text { Ic }=12,57 \frac{\mathrm{A}}{\mathrm{p}^{2}}\end{array}$ & $\begin{array}{l}\text { Christofoletti } \\
\quad(1980)\end{array}$ & $\begin{array}{l}\text { Relação entre a área da bacia com a área de um círculo de perímetro } \\
\text { igual ao da bacia, } \\
\text { varia de } 0 \text { a } 1 \text {, tendendo para a unidade à medida que a bacia se } \\
\text { aproxima da forma circular. }\end{array}$ \\
\hline $\begin{array}{l}\text { Fator de forma } \\
\qquad \mathrm{Kf}=\frac{A}{L^{2}}\end{array}$ & $\begin{array}{l}\text { Villela e Mattos } \\
\qquad(1975)\end{array}$ & $\begin{array}{l}\text { Relaciona a forma da bacia com um retângulo, logo, uma bacia } \\
\text { com fator de forma baixo indica que a mesma tende a ser estreita e } \\
\text { longa, e, portanto, menos sujeita a enchentes que outra, de mesmo } \\
\text { tamanho com fator de forma maior. Por outro lado, bacias com Kf } \\
\text { próximo a } 1 \text { tendem a forma circular. }\end{array}$ \\
\hline $\begin{array}{l}\text { Densidade de drenagem } \\
\qquad \mathrm{Dd}=\frac{L t}{A}\end{array}$ & $\begin{array}{l}\text { Christofoletti } \\
\quad(1980)\end{array}$ & $\begin{array}{l}\text { Quanto maior o índice, mais rapidamente a água é drenada para } \\
\text { o exutório. Em igualdade dos restantes fatores, quanto maior } \\
\text { a densidade de drenagem maior a tendência de escoamento } \\
\text { superficial e ocorrência de cheias, uma vez que se favorece o } \\
\text { transporte da água em detrimento da infiltração. }\end{array}$ \\
\hline $\begin{array}{l}\text { Relação de relevo } \\
\qquad \mathrm{Rr}=\mathrm{H} / \mathrm{Lx}\end{array}$ & Schumm (1956) & $\begin{array}{l}\text { Quanto maior o valor de } \mathrm{Rr} \text {, maior será o desnível entre a cabeceira } \\
\text { e o exutório, consequentemente maior será a declividade média da } \\
\text { bacia. }\end{array}$ \\
\hline $\begin{array}{l}\text { Índice de rugosidade } \\
\qquad \mathrm{Ir}=\mathrm{H} \times \mathrm{Dd}\end{array}$ & Strahler (1964) & $\begin{array}{l}\text { Quanto maior o Ir, maior energia e/ou alta transmissibilidade do } \\
\text { terreno. }\end{array}$ \\
\hline
\end{tabular}


A avaliação destes resultados de modo a caracterizar a forma e o relevo das sub-bacias foi realizada através da classificação dos resultados e atribuição de pesos, de acordo com os significados compreendidos através das referências, conforme o Quadro 2, respectivamente.

Quadro 2. Avaliação do formato da bacia

\begin{tabular}{|c|c|c|c|c|}
\hline $\begin{array}{c}\text { Coeficiente de } \\
\text { Compacidade (Kc) }\end{array}$ & Índice de Circularidade (Ic) & Fator de Dorma (Kf) & Forma & Peso \\
\hline $\mathrm{Kc} \geq 3$ & $0,1 \geq \mathrm{Ic}>0,3$ & $0,1 \geq \mathrm{Kf}>0,3$ & muito alongada & 4 \\
\hline $3>\mathrm{Kc} \geq 2$ & $0,3 \geq \mathrm{Ic}>0,5$ & $0,3 \geq \mathrm{Kf}>0,5$ & alongada & 3 \\
\hline $2>\mathrm{Kc} \geq 1$ & $0,5 \geq \mathrm{Ic}>0,8$ & $0,5 \geq \mathrm{Kf}>0,8$ & pouco alongada & 2 \\
\hline Próximo a 1 & $\mathrm{Ic} \geq 0,8$ & $\mathrm{Kf} \geq 0,8$ & quase circular & 1 \\
\hline
\end{tabular}

Fonte: Autoria própria (2020).

Após avaliar cada índice calculou-se a média dos pesos, que indicou as sub-bacias com maior tendência a picos de cheia, ou seja, mais circulares e as que podem provocar estes picos na bacia a jusante, ou seja, com maior transmissibilidade, conforme o Quadro 3.

Quadro 3. Avaliação da transmissibilidade do terreno

\begin{tabular}{|c|c|c|c|}
\hline Índice de Rugosidade (Ir) & Relação de Relevo $(\mathbf{R r})$ & Transmissibilidade & Peso \\
\hline 1 a 50 & 1 a 5 & Muito baixa & 1 \\
\hline 50 a 100 & 5 a 10 & Baixa & 2 \\
\hline 100 a 250 & 10 a 20 & Média & 3 \\
\hline 250 a 400 & 20 a 50 & Alta & 4 \\
\hline Acima 400 & Acima de 50 & Muito alta & 5 \\
\hline
\end{tabular}

Fonte: Autoria própria (2020).

\section{Análise temporal do uso e cobertura do solo}

Os mapeamentos foram obtidos na plataforma de monitoramento de cobertura do solo subsidiada pelo Fórum Florestal do Sul e Extremo Sul da Bahia (Ribeiro et al. 2012) no qual as informações mapeadas encontram-se disponíveis em arquivos vetoriais.

Para avaliar estes dados foi utilizado o software QGIS 2.18, em que o arquivo foi reprojetado para o sistema de projeção cilíndrica Universal Transversa de Mercator (UTM), DATUM SIRGAS2000 e fuso 24 Sul. Foi realizada uma análise exploratória para identificar as classes com áreas naturais de baixa cobertura vegetal, usos antrópicos e vegetação florestal. A variação temporal das áreas em cada classe foi avaliada entre os anos de 1990, 2001, 2007 e 2013. O último mapeamento cobre parcialmente a área da bacia.

A partir da descrição das classes identificadas, quantificou-se a cobertura mais recente em cada sub-bacia identificando as classes mais expressivas, então se pontuou o nível de impacto direto nos recursos hídricos, de baixo (1) a muito alto (4). 
Análise da disponibilidade hídrica

A distribuição pluviométrica e as séries de vazão na bacia foram analisadas a partir dos dados disponibilizados pelo portal Hidroweb (ANA 2020). Foram selecionados os dados das estações pluviométricas com até $30 \mathrm{~km}$ de distância dos divisores de água da bacia. Os dados foram organizados em tabelas para cálculo da precipitação pluviométrica anual e mensal médias. Os dados de pluviometria total anual média foram importados para o software QGIS 2.18 e procedida a interpolação utilizando o método geoestatístico Krigagem Ordinária, descrito por Thompson (1992) para a espacialização desta característica na bacia hidrográfica. A pluviometria foi pontuada de acordo com a precipitação anual média em cada sub-bacia, sendo considerada: muito alta (acima de $1100 \mathrm{~mm}$ ), alta (acima de $1.000 \mathrm{~mm}$ ), média (acima de $900 \mathrm{~mm}$ ) e baixa (inferior a $900 \mathrm{~mm}$ ).

As séries de vazão diária que foram registradas nas três estações fluviométricas ao longo do rio Buranhém também foram avaliadas, a fim de calcular as vazões médias, máximas e mínimas. Através da análise de frequência foi calculada a vazão de permanência em $95 \%$ do tempo $\left(Q_{95}\right)$ da série histórica. Estas vazões foram utilizadas para constatar as tendências de escoamento superficial verificadas na avaliação morfométrica.

Compartimentalização fisiográfica da bacia hidrográfica

As características das sub-bacias foram analisadas, buscando agrupá-las de acordo com as semelhanças do ponto de vista hidrológico. Desta forma segmentou-se a bacia a partir do potencial de provocar impactos ambientais atribuindo às características estudadas os pesos: forma (1); transmissibilidade (2); precipitação média anual (3) e uso do solo (4).

\section{Resultados e discussão}

A área total da bacia é de $2.595 \mathrm{~km}^{2}$, subdividida em 9 sub-bacias, compondo $42 \%$ da Região de planejamento e gestão das Água IV da Bahia (Figura 1). Sendo a bacia a área de captação da água da chuva, esta define o volume de água recebido, e portanto sua potencialidade hídrica, que por sua vez, quando associada à morfometria e aos usos do solo, subsidia conclusões acerca da disponibilidade ou escassez hídrica (Alves et al. 2019). Nesse sentido, destacamos que a distribuição de chuvas é variável na região, sendo observados os maiores totais anuais próximos ao litoral devido à influência dos sistemas meteorológicos, tropicais e extratropicais, que atuam sobre a América do Sul (Chaves 1999). A precipitação é menor nas estações localizadas nas maiores longitudes (Oeste), porém também se observam índices elevados na estação localizada ao Sudoeste da bacia, em Itamaraju. A interpolação dos dados mostrou que a porção Sul da bacia recebe maiores volumes de chuva (Figura 2).

A topografia forma uma rede de drenagem e define áreas com diferentes tendências. $\mathrm{O}$ rio Buranhém drena as sub-bacias 9, 7, 5, 2 e 1 com precipitações anuais de 1005 mm, 1053 mm, 967 $\mathrm{mm}, 931 \mathrm{~mm}$ e $1536 \mathrm{~mm}$, respectivamente. A sazonalidade das chuvas também varia na região, com estação seca, de maio a agosto, mais marcada nas maiores longitudes. A região da sub-bacia 3, com precipitação anual média de $1030 \mathrm{~mm}$, atua na manutenção da perenidade do rio, visto que sua maior contribuição ocorre no período de estiagem nas sub-bacias superiores. 
Figura 2. Sub-bacias do rio Buranhém: cursos d’agua e Precipitação média anual (mm).
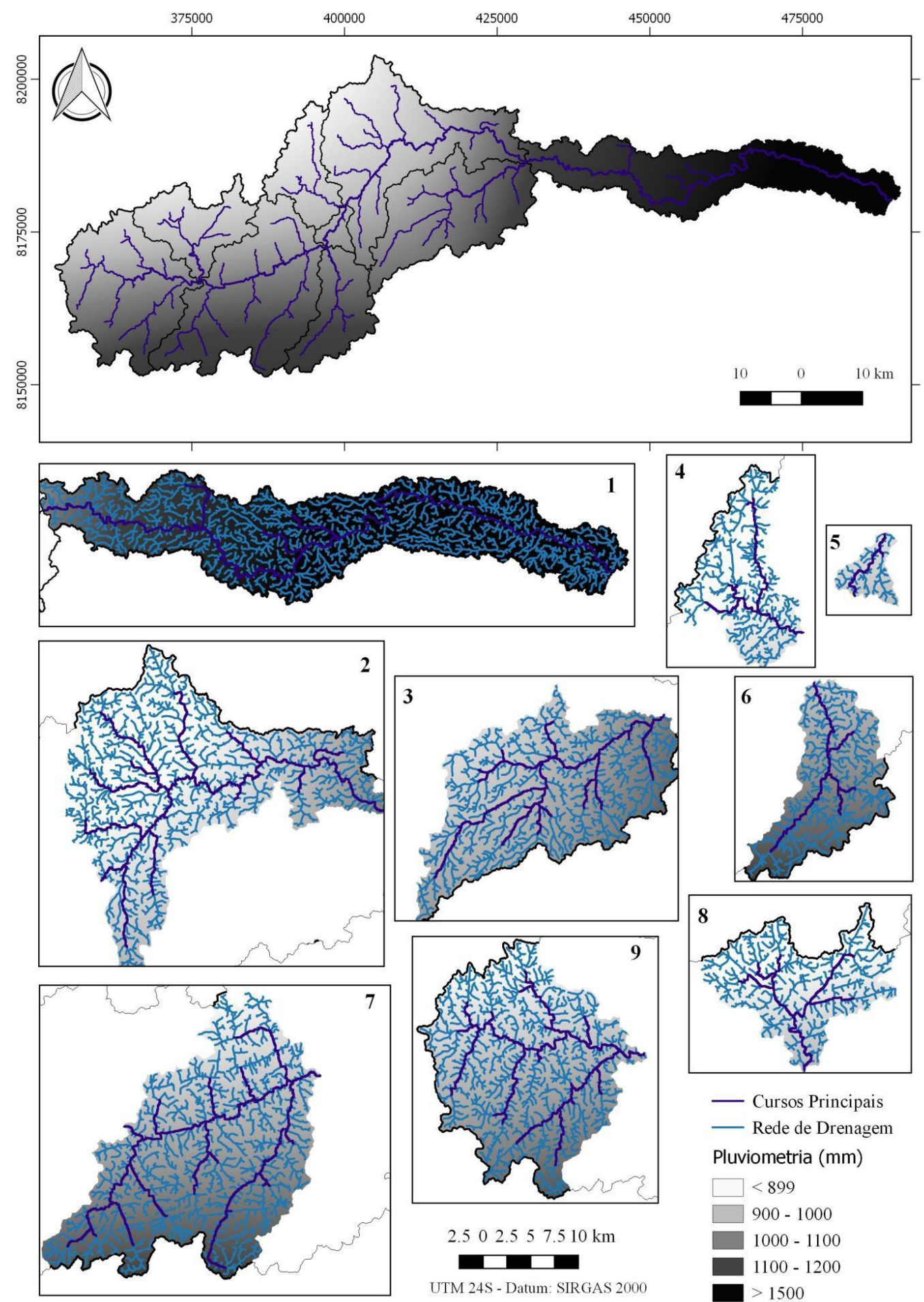

A bacia do rio Buranhém apresenta morfometria alongada estreita e irregular, conforme a delimitação espacial da Figura 2 e pelos parâmetros de índice de circularidade e fator de forma, no Quadro 4. 
Quadro 4. Parâmetros morfométricos da bacia do rio Buranhém e sub-bacias

\begin{tabular}{|c|c|c|c|c|c|c|c|c|c|c|c|c|}
\hline & $\mathbf{A}$ & $\mathbf{P}$ & $\mathbf{L x}$ & $\mathbf{H}$ & $\mathbf{L t}$ & $\mathbf{K c}$ & $\mathbf{I c}$ & $\mathbf{K f}$ & $\mathbf{D d}$ & $\mathbf{I r}$ & $\mathbf{R r}$ & \multirow{2}{*}{ Forma } \\
\hline Un. & $\mathrm{km}^{2}$ & $\mathrm{~km}$ & $\mathrm{~km}$ & $\mathrm{~m}$ & $\mathrm{~km}$ & $*$ & $*$ & $*$ & $\mathrm{~km} / \mathrm{km}^{2}$ & $*$ & $*$ & Auito alongada \\
\hline 1 & 442,9 & 262,1 & 62,1 & 146,0 & 874,5 & 3,5 & 0,1 & 0,1 & 2,0 & 73,9 & 2,4 & Alongada \\
\hline 2 & 471,8 & 208,8 & 30,2 & 132,0 & 796,1 & 2,7 & 0,1 & 0,5 & 1,7 & 78,2 & 4,4 & Alongada \\
\hline 3 & 342,4 & 153,8 & 33,8 & 634,0 & 568,8 & 2,3 & 0,2 & 0,3 & 1,7 & 381,6 & 18,8 & Alongada \\
\hline 4 & 137,9 & 97,9 & 18,0 & 796,0 & 243,3 & 2,3 & 0,2 & 0,4 & 1,8 & 451,2 & 44,2 & \\
\hline 5 & 28,4 & 37,5 & 7,3 & 31,0 & 51,9 & 2,0 & 0,3 & 0,5 & 1,8 & 17,0 & 4,2 & Pouco alongada \\
\hline 6 & 160,1 & 100,1 & 21,7 & 653,0 & 285,9 & 2,2 & 0,2 & 0,3 & 1,8 & 365,7 & 30,1 & Alongada \\
\hline 7 & 471,2 & 182,1 & 21,5 & 648,0 & 778,0 & 2,3 & 0,2 & 1,0 & 1,7 & 392,5 & 30,1 & Pouco alongada \\
\hline 8 & 170,0 & 112,9 & 18,8 & 709,0 & 288,9 & 2,4 & 0,2 & 0,5 & 1,7 & 417,2 & 37,7 & Alongada \\
\hline 9 & 368,2 & 149,3 & 24,3 & 933,0 & 638,0 & 2,2 & 0,2 & 0,6 & 1,7 & 538,4 & 38,4 & Alongada \\
\hline TOTAL & $2.595,1$ & 680,2 & 138,2 & $1.198,0$ & $4.526,3$ & 3,7 & 0,1 & 0,1 & 1,9 & 686,9 & 8,7 & Muito alongada \\
\hline
\end{tabular}

Onde: Un.= unidades; ${ }^{\star}=$ parâmetros adimensionais; $\mathrm{A}=$ Área; $\mathrm{P}=$ Perímetro; $\mathrm{Lx}=$ Comprimento Axial; $\mathrm{H}=$ Amplitude Altimétrica; Lt = Comprimento dos Canais; Dm = Declividade média; Kc = Coeficiente de compacidade; Ic = Índice de Circularidade; Kf = Fator de forma; Dd = Densidade de drenagem; Ir = Índice de rugosidade; Rr = Relação de Relevo.

A densidade de drenagem da bacia é um importante indicador geomorfológico, variando de acordo com elementos da topografia que produzem os canais de drenagem (Strahler 1964). Segundo Souza e Rodrigues (2012), esse índice pode variar de 0,5 e $2 \mathrm{~km} / \mathrm{km}^{2}$ caracterizando bacias com drenagem mediana e entre 2 e $3,5 \mathrm{~km} / \mathrm{km}^{2}$ bacias bem drenadas, estando diretamente relacionado com o Ir, que por sua vez representa a forma de relevo predominante. Desta forma, afirma-se que a bacia do rio Buranhém possui média capacidade de drenagem.

As sub-bacias (1, 2 e 9) do Buranhém possuem forma alongada e irregular, o que é um indicativo de baixa ocorrência de enchentes (Lopes et al. 2018). Porém as sub-bacia 5 e 7, podem ser consideradas pouco alongadas, sendo estas as sub-bacias que apresentam dinâmica morfométrica que mais influenciam no regime de escoamento. Por outro lado, os índices de rugosidade elevados também indicam vulnerabilidade à inundações (Sarkar et al. 2020), como observado nas subbacias 9, 4, 8, 7, 6 e 3, nesta ordem. Cabe ressaltar que o Ir, por caracterizar o relevo, associa-se ao escoamento superficial. Esta característica permite avaliar as sub-bacias com relação à fragilidade natural, sem levar em conta as condições de cobertura vegetal, classe de solo e precipitação (Almeida et al. 2018).

Semelhantemente, a $\mathrm{Rr}$, caracteriza a declividade e a sua capacidade de transportar água e sedimentos (Kabite et al. 2018; Sarkar et al. 2020). Desta forma, valores elevados mostram presença de áreas montanhosas e valores baixos indicam áreas de vales (Mundetia et al. 2018). As sub-bacias que apresentaram maiores razões foram, respectivamente, 4, 9, 8, 7 e 6 .

Estes índices não devem ser avaliados isoladamente, mas sim para complementar a análise integrada dos fatores que influenciam no sistema, como as características de declive apresentadas na Figura 3. 
Figura 3. Classes de declividade segundo a classificação da EMBRAPA (2006)
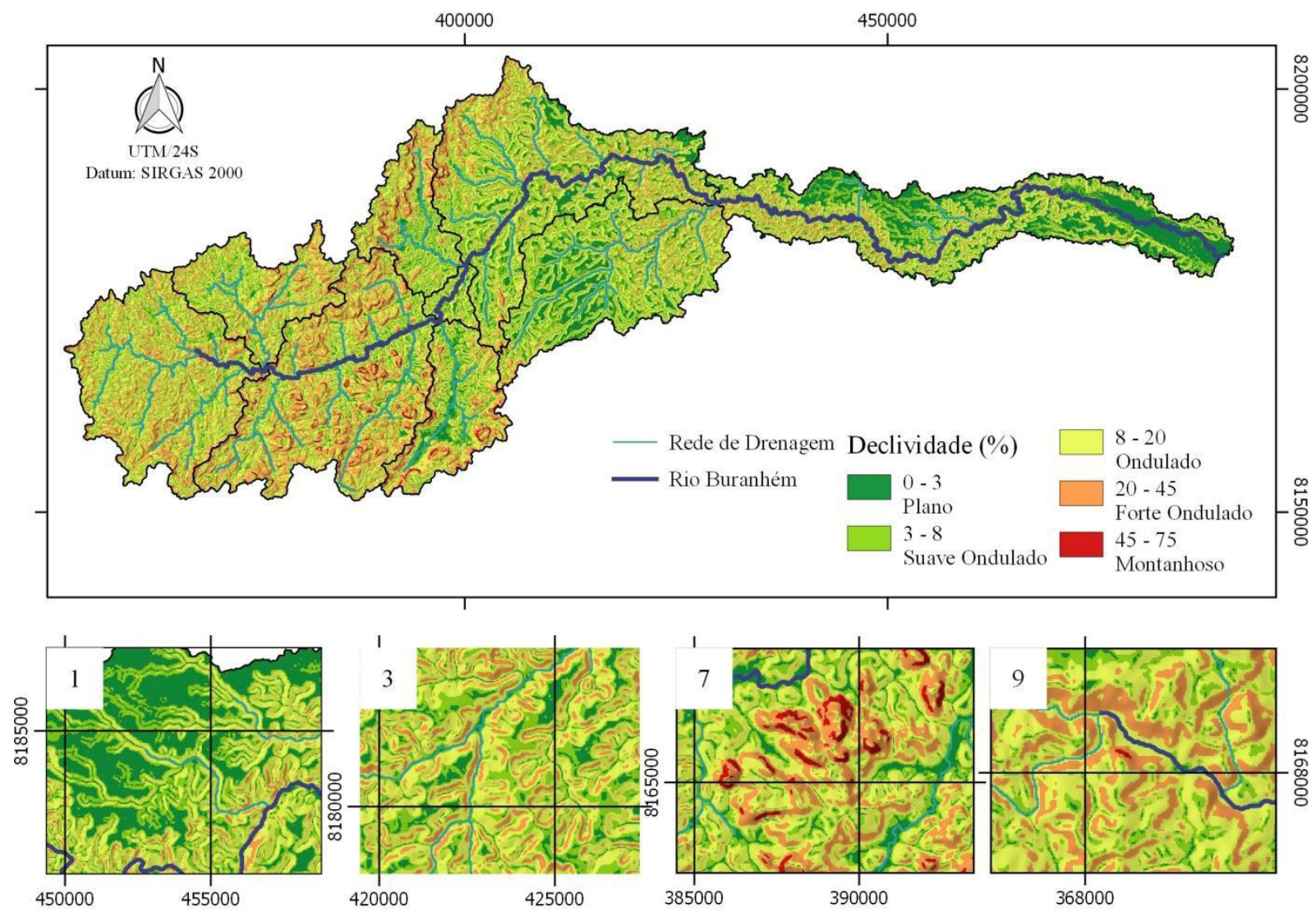

As maiores declividades ocorrem nas sub-bacias 7 e 4, onde verificam-se formas de relevo montanhoso, já as sub-bacias 8 e 9 apresentam relevo forte ondulado predominante e bem distribuído na área. Corroborando com a discussão sobre a relação de relevo, observa-se que a sub-bacia 4 apresenta picos montanhosos na região do divisor de águas, e uma elevada amplitude altimétrica, enquanto a 9 e a 8 , apesar de o relevo ser predominante menos acentuado, a Rr destas sub-bacias também é alta, devido aos valores elevados de H. Por outro lado, na sub-bacia 7, mesmo com a predominância do relevo montanhoso, o Ir e a Rr são menores do que as demais, isto ocorre pela menor amplitude altimétrica observada no trecho do rio, posto que as formações do relevo estão distribuídas em toda a área.

A região superior da sub-bacia 3 apresenta relevo predominantemente plano enquanto a porção inferior é fortemente ondulada, influenciando os padrões de drenagem que resulta em um elevado Ir mesmo com uma Rr menos expressiva. As áreas planas ocorrem principalmente nos tabuleiros, vales e próximo à foz do rio onde a agricultura e a silvicultura são favorecidas. Apesar do relevo acentuado próximo aos divisores de água da bacia, a sub-bacia 2 apresenta relevo suave ondulado, com Ir e Rr baixos, enquanto para a sub-bacia 1, as maiores declividades ocorrem apenas nas vertentes e talvegues.

Ao associar morfometria com topografia, percebe-se que diversos fatores podem influenciar na dinâmica hidrológica direta ou indiretamente, sendo as bacias hidrográficas sistemas complexos. Em regiões com serras e picos, por exemplo, pode haver formação de chuvas orográficas, que devido 
à sua curta duração e alta intensidade, associado a um menor tempo de concentração, apresentam alto potencial para causar enchentes logo a jusante (Lorenzon et al. 2015). Além disso, quanto maior a declividade, maior o escoamento superficial, fazendo com que a umidade do solo seja pouco utilizada na regulação dos volumes e na evapotranspiração da vegetação (Tucci e Mendes 2006). Assim, para o planejamento territorial e conservação dos atributos hídricos, físicos e bióticos das bacias hidrográficas, chama-se atenção para a integração com outras características, como orientação do terreno e sua exposição ao vento e à incidência solar, tipos de solos, atividades desenvolvidas e seus quantitativos de vegetação, padrões de precipitação e evapotranspiração, e produtividade de água subterrânea (Lopes et al. 2018). Portanto, inúmeras discussões podem ser iniciadas a partir da análise morfométrica, partindo da compreensão dos processos hidrogeomorfológicos como uma análise global, para a setorização dos seus elementos básicos e a participação isolada dos demais fatores (Milani e Canali 2000).

As atividades desenvolvidas na bacia precisam considerar estes aspectos. A agropecuária, pecuária, por exemplo, devem utilizar práticas criteriosas de conservação do solo, que vão desde medidas mais simples, em regiões com relevo suave-ondulado, como renques de vegetação permanente, cordões em contorno, canais escoadouros, cobertura morta, rotação de culturas, adubação verde e plantio direto, até técnicas conservacionistas avançadas nas áreas com relevo ondulado e forte-ondulado, como, lavoura mínima, lavoura nula e cobertura do solo contínua (Alves et al. 2019).

De maneira geral, a região onde a bacia do rio Buranhém está localizada apresenta um histórico de desmatamento e exploração da madeira da Mata Atlântica, substituída pelo cultivo de café e o cacau, no final do século XVIII (SEI 2015). Um estudo utilizando os dados de Ribeiro et al. (2012), constatou que mais da metade dos fragmentos florestais são considerados pequenos, chamando atenção para o desmatamento nas Áreas de Preservação Permanente (APPs), especialmente no entorno das nascentes na região do alto curso, que intensifica a fragmentação e interfere no regime de águas da bacia hidrográfica (Azevedo et al. 2016). Atividades como o "Programa de Reflorestamento da Mata Atlântica Bahia", a diversificação das culturas e expansão da agroecologia (Dutra et al. 2012) têm sido implantados para mitigar e reduzir a fragmentação na área.

A Figura 4 apresenta a distribuição temporal do mapeamento do uso do solo, revelando um sistema intensivo de uso da superfície terrestre, cuja matriz da paisagem é a pastagem. 
Figura 4. Uso e ocupação do solo em 1990, 2001, 2007 e 2013.

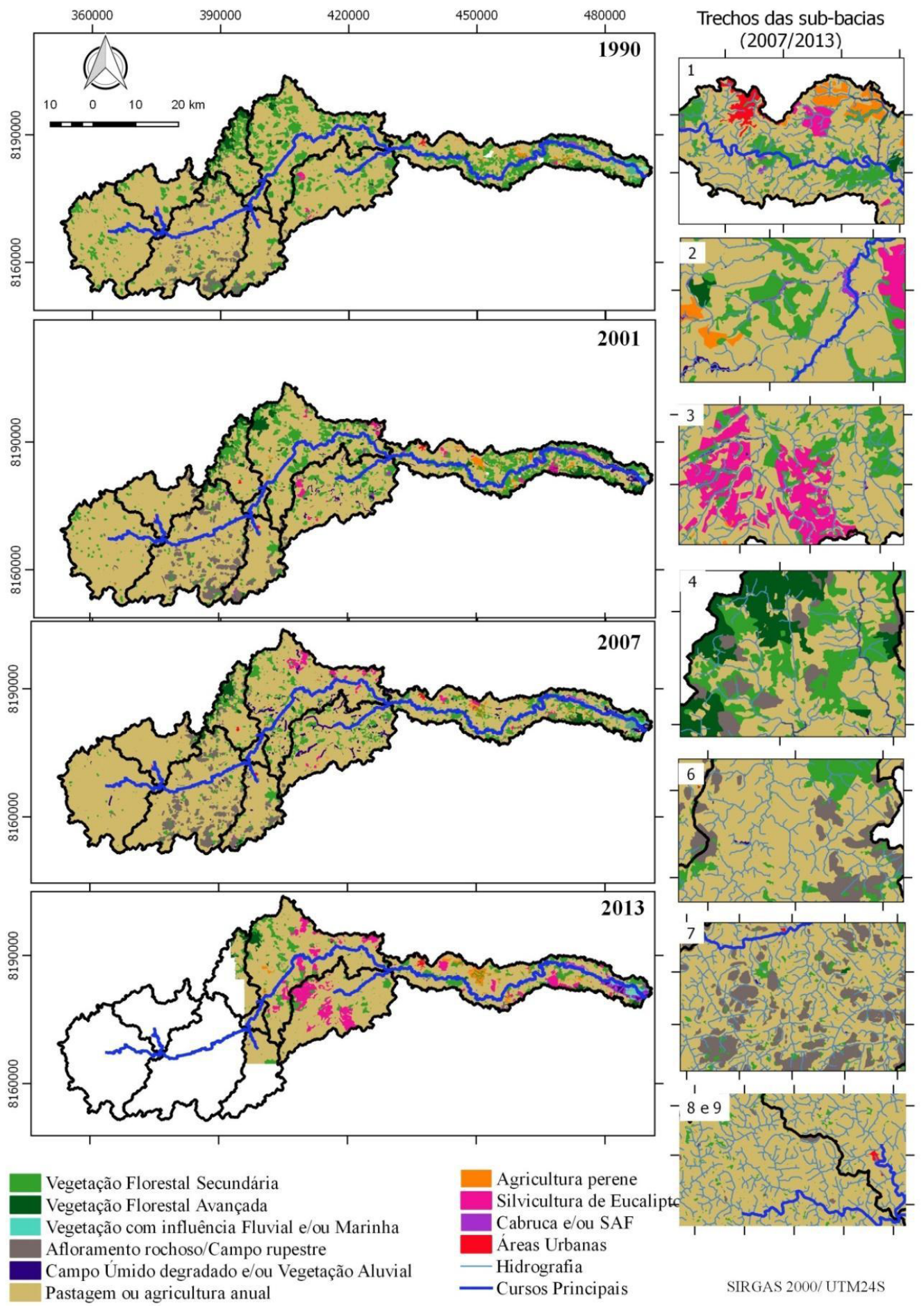

Os fragmentos florestais próximos ao litoral se mantiveram preservados, como observado em mapas históricos produzidos por Mendonça et al. (1994). Entre as décadas de 60 e 70 ocorreram transformações socioeconômicas na região promovidas pela integração com a economia estadual e nacional facilitada pela implantação da rodovia federal BR-101 que resultou em nova dinâmica (Almeida et al. 2008). Além disso, o desmatamento ocorreu com maior intensidade na região Oeste, favorecida pela agropecuária, mais desenvolvida em Minas Gerais. O último Censo Agropecuário mostrou que em Porto Seguro 38\% das unidades produtivas estão ocupadas por pastagens, enquanto 
Eunápolis perfazem 44\%, já Santo Antônio do Jacinto apresentou um percentual de $83 \%$, sendo a pecuária bovina a principal atividade, assim como em Guaratinga, com $72 \%$, onde se encontra um dos maiores rebanhos da Bahia, com quase 109 mil cabeças (IBGE 2017).

Este estudo foi atualizado em 2013 e, apesar de não cobrir toda a extensão da bacia, avaliou as mudanças do uso e ocupação do solo que ocorreram na bacia do rio Buranhém, considerando as sobreposições dos mapeamentos de 2007 e 2013, evidenciando a conversão das pastagens em eucalipto (4,65\%) e vegetação em estágio inicial (5,91\%) (Ribeiro et al. 2015). Observou-se que a área total de silvicultura de eucalipto aumentou em $60 \mathrm{~km}^{2}$ e que houve recomposição da vegetação florestal, inclusive com formações secundárias em estágio avançado. Verifica-se que a região onde se encontram a maior parte dos campos úmidos degradados é ocupada atualmente pela silvicultura de eucalipto. E nesse sentido, ressalta-se a necessidade de readequação conforme o Código Florestal (Brasil 2012).

A região inferior do Buranhém apresenta uma paisagem mais diversificada, onde a agricultura e os cultivos agroflorestais são permeados por fragmentos em diferentes estágios de sucessão ecológica. Neste trecho da bacia, o uso e ocupação do solo contribuem para a formação dos "Mosaicos Florestais Sustentáveis" (Dutra et al. 2012).

Tratando-se de disponibilidade hídrica, ou seja, a distribuição do deflúvio ao longo do tempo, é importante destacar a influência do uso e cobertura do solo na resposta hidrológica das bacias, sendo objeto de muitos estudos de modelagem hidrológica e ambiental. Nesse sentido, cabe lembrar que as relações são tipicamente não lineares e complexas. O desmatamento, por exemplo, causa uma redução da evapotranspiração, que pode ser contrabalanceada pela regeneração florestal, visto que a menor cobertura favorece o escoamento superficial e as vazões de pico na estação chuvosa, enquanto as vazões na estação seca estão associadas às condições de infiltração (Costa et al. 2003), que por sua vez, estão associadas à geologia e à morfometria e influenciam na recarga dos aquíferos para a manutenção do fluxo de base (Kabite et al. 2018).

$\mathrm{Na}$ região do Parque Nacional do Alto Cariri, que abrange o Norte das sub-bacias 2, 4 e 8 estão localizados a maior parte dos fragmentos florestais em estágio avançado e diversas nascentes que contribuem para a perenidade do rio Buranhém. Especialmente na sub-bacia 4, a vegetação desempenha um papel importante na interceptação da água da chuva, visto que o relevo montanhoso aumenta a energia do escoamento. O relevo plano favoreceu a implantação da silvicultura do eucalipto nas sub-bacias 2 e 3 e nas partes mais onduladas a pastagem é permeada por fragmentos florestais em estágio inicial ou médio de regeneração. Essas áreas onde a vegetação de maior porte diminui a transmissibilidade e energia do escoamento tem um importante papel no amortecimento do escoamento e favorecem a recarga hídrica para as regiões subjacentes.

Conhecer a relação entre uso do solo e declive auxilia, não apenas no cumprimento da legislação, mas também no planejamento adequado do uso do solo para a prevenção à perda de solo e aumento da recarga dos aquíferos, determinando as atividades propícias às condições naturais locais e as práticas de manejo mais adequadas (Oliveira et al. 2011; Lopes et al. 2018; Alves et al. 2019). O desmatamento elevado e a prática intensiva da agropecuária ao longo do tempo, associado às características do relevo, especialmente nas sub-bacias 5, 6, 7, 8 e 9, resultaram em pastagens degradadas, reduzindo a sua produtividade, o que pode ser verificado no censo agropecuário, e causando desequilíbrios no sistema hídrico. 
Foram verificadas diferentes tendências naturais e antrópicas, fatores estes que podem ser intensificados por mudanças na pluviometria e retirada da cobertura do solo. O Quadro 5 apresenta a avaliação destas tendências de acordo com os critérios discutidos.

Quadro 5. Potencial de causar impactos ambientais.

\begin{tabular}{|c|c|c|c|c|c|}
\hline PESO & 1 & 2 & 3 & 4 & Pontuação \\
\hline Sub-bacias & Forma & Transmissibilidade & Uso do solo & Pluviosidade & Média \\
\hline 4 & 3,3 & 4,5 & 1 & 1 & 1,9 \\
\hline 2 & 3,3 & 1,5 & 2 & 2 & 2,0 \\
\hline 5 & 2,7 & 1,0 & 3 & 2 & 2,3 \\
\hline 1 & 4,0 & 1,5 & 2 & 4 & 2,7 \\
\hline 8 & 3,3 & 4,5 & 3 & 2 & 3,0 \\
\hline 3 & 3,7 & 3,5 & 3 & 3 & 3,2 \\
\hline 6 & 3,7 & 4,0 & 3 & 3 & 3,3 \\
\hline 9 & 3,0 & 4,5 & 3 & 3 & 3,3 \\
\hline 7 & 2,7 & 4,0 & 4 & 3 & 3,6 \\
\hline
\end{tabular}

O escoamento superficial é governado pela gravidade, assim quanto maior a diferença de altura, maior a energia potencial, neste aspecto, a transmissibilidade do terreno está associada com a energia do escoamento, que é transmitida na bacia hidrográfica e através dos rios, portanto, quanto maior a energia, maior a suscetibilidade à erosão (Milani e Canali, 2000; Oliveira et al. 2011), além disto, as áreas de contribuição com características de elevada transmissibilidade e energia de fluxo podem provocar inundações no trecho logo a jusante, principalmente em subbacias menos alongadas (Cajazeiro 2012). Neste caso chama-se atenção para a sub-bacia 5, que recebe, os escoamentos das bacias 4, 6 e 7, sendo, portanto, o trecho do rio Buranhém com maior tendência a inundações. Por sua vez, este acúmulo de escoamento pode ser transferido para a bacia 2, que apresenta baixa transmissibilidade e energia, e portanto, apesar de sua forma alongada, a ocorrência de inundações na bacia e a jusante depende de fatores como a ocorrência de chuvas concentradas nas bacias superiores, que possuem maior transmissibilidade.

Corroborando para esta discussão, a análise das vazões mostrou que o rio Buranhém é pouco regularizado, ou seja, apresenta cheias muito maiores que as vazões médias e assim como mínimas muito baixas nos períodos de estiagem. O monitoramento é realizado nas sub-bacias 1 e 2 . As vazões no ponto mais à montante apresentaram maiores amplitudes entre máximas $\left(352 \mathrm{~m}^{3} / \mathrm{s}\right)$ e mínimas $\left(3 \mathrm{~m}^{3} / \mathrm{s}\right.$ ), e menor vazão de permanência em $95 \%$ do tempo (Q95 = 1,1 m $\left.{ }^{3}, \mathrm{~s}\right)$, o que indica que neste ponto a disponibilidade hídrica é ainda menor e as cheias são mais expressivas. A maior série de dados demonstrou vazões máximas em torno de $193 \mathrm{~m}^{3} / \mathrm{s}$ e mínimas de $6 \mathrm{~m}^{3} / \mathrm{s}$, esta amplitude está associada à variabilidade da precipitação e à baixa contribuição do escoamento subterrâneo, bem como ao elevado escoamento superficial, que resulta na menor recarga dos aquíferos. 
A consolidação das características ambientais e antrópicas da bacia permitiram verificar algumas semelhanças com relação às sub-bacias, desta forma, considerando o potencial para causar impactos no rio Buranhém recomenda-se a divisão da bacia em 4 regiões (Figura 5)

Figura 5. Divisão fisiográfica da bacia do Buranhém.

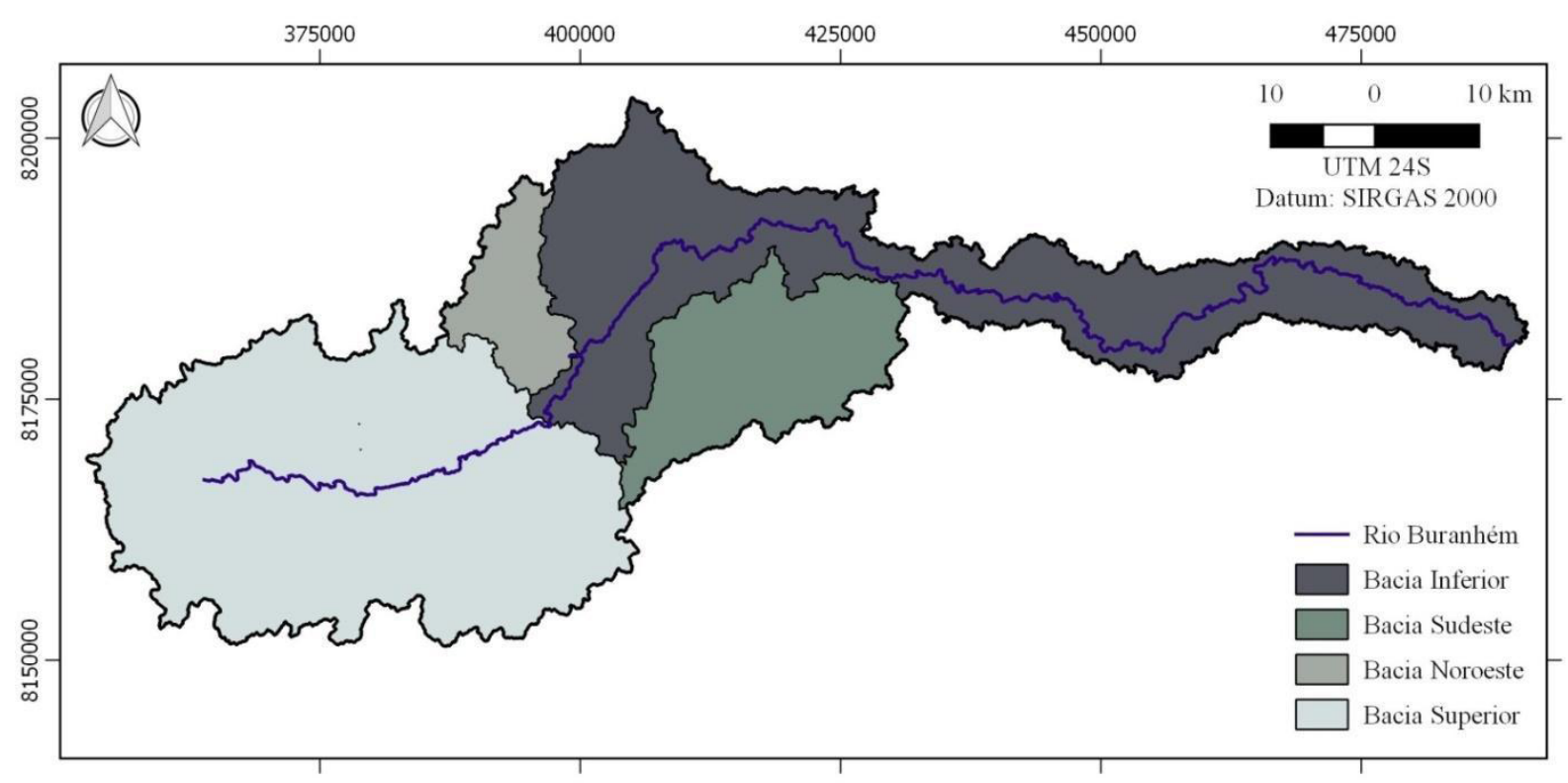

As sub-bacias superiores, 6, 7, 8 e 9, compõe a região da cabeceira, apresentam relevo que varia de ondulado a montanhoso, menores índices pluviométricos e cobertura vegetal esparsa. O armazenamento de água não é favorecido, visto que o escoamento superficial é o fenômeno predominante. Pelo histórico de uso do solo na região, trata-se de uma região intensamente antropizada. Na porção final desta região o relevo é mais acentuado e marcado por picos rochosos, devido a esta característica, as pastagens tornam-se menos produtivas, aumentando o risco de degradação do solo, erosão, perda de solo e assoreamento dos cursos d'água a jusante. Além disto, a transmissibilidade e a forma contribuem para a ocorrência dos picos de vazão máxima na região inferior. Portanto recomenda-se a adoção de práticas conservacionistas mais restritivas como cultivos em nível, a recomposição de APPs de taludes e topos de morro, e também medidas que retardem o tempo de concentração, de modo a aumentar a disponibilidade de água, como por exemplo, barraginhas e barragens subterrâneas.

Na sub-bacia 4 estão os maiores fragmentos florestais do PARNA Alto Cariri, onde o relevo varia de ondulado a montanhoso e a precipitação é menor, nesta região a preservação da vegetação é de suma importância, e a recuperação das APPs de curso hídrico deve ser uma medida prioritária, visto que a área apresenta importância do ponto de vista da preservação da biodiversidade e estes podem tornar-se corredores ecológicos. A preservação dos fragmentos florestais do Parque Nacional Alto do Cariri pode ser justificada em seu plano de manejo, tendo em vista a importância deste para preservação dos recursos hídricos.

A sub-bacia 3 possui características que favorecem a infiltração de água e recarga do aquífero, o que associada aos maiores índices pluviométricos e na sua distribuição ao longo do ano, resulta numa maior produtividade hídrica, sendo esta bacia essencial para a manutenção da regularidade das vazões. 
É a região que apresentou maiores transformações nos últimos anos, onde a paisagem apresenta os maiores fragmentos de silvicultura e vegetação florestal secundária. Recomendam-se medidas para preservação e recuperação das áreas de recarga e o estudo do balanço hídrico nesta região, bem como a instalação de um posto fluviométrico no córrego Itu para avaliar o potencial de contribuição dele.

A região inferior é composta pelas sub-bacias 1,2 e 5, e é a que possui forma mais alongada, com relevo que varia de plano a ondulado, o que resulta na menor concentração do deflúvio. Os tabuleiros costeiros e vales fluviais têm a produtividade hídrica favorecida pelo aquífero Barreiras. Ao passo que é a região com maior demanda hídrica, devido à proximidade com os centros urbanos de Porto Seguro e Eunápolis. A elevada pluviosidade é mais influenciada pelo oceano Atlântico. Encontra-se também a maior diversidade de usos do solo e alguns pequenos fragmentos florestais. Os efeitos da degradação do solo a montante das bacias podem refletir no assoreamento do rio nesta região, principalmente em locais mais planos, onde o curso d'água passa a ser mais sinuoso, favorecendo a deposição dos sedimentos. Recomendam-se medidas para favorecer a qualidade e disponibilidade de água nesta região, como o controle da poluição, a preservação e recuperação de APPs e proteção das áreas de recarga dos aquíferos.

\section{Conclusão}

As características fisiográficas mostraram que a bacia hidrográfica do rio Buranhém apresenta escoamento superficial favorecido. Isto tende a causar impactos ambientais e foi demonstrado pela baixa regularidade das vazões e a ocorrência de cheias de grande magnitude, sendo necessária a adoção de medidas conservacionistas para aumentar a disponibilidade hídrica e reduzir a degradação do solo, diminuindo o tempo de concentração e favorecendo a recarga dos aquíferos.

A divisão em regiões permitiu identificar as principais ameaças à qualidade e quantidade dos recursos hídricos, sendo uma importante ferramenta para o planejamento ambiental. Todavia, este estudo não encerra as discussões sobre a complexidade das inter-relações existentes neste território.

\section{Agradecimentos}

Ao Programa de Pós-Graduação da Universidade Federal do Sul da Bahia, PPGCTA/UFSB.

Participação dos autores: GMFS - coleta, tratamento e processamento dos dados; análise e discussão dos resultados; ERNL - revisão da metodologia adotada, organização e revisão de texto; FBZ - organização, metodologia, análise de resultados e revisão de texto; JBLS - organização, análise de resultados e revisão de texto.

Aprovação ética ou licenças de pesquisa: Entendemos que esta pesquisa não necessita de aprovação ética ou licenças visto que não envolve animais ou humanos, e ainda, dispensa autorização de órgão ambientais ou afins.

Disponibilidade dos dados: os dados analisados neste trabalho foram obtidos em fontes de acesso público e repositórios, devidamente referenciados ao longo do texto. O estudo é originário de pesquisa de pós-graduação com dissertação disponível no repositório institucional da Universidade Federal do Sul da Bahia (https://sig.ufsb.edu.br/ sigaa/verArquivo?idArquivo=344824\&key=a670a50adae3a27a08f8d6df12a91990).

Fomento: Coordenação de Aperfeiçoamento de Pessoal de Nível Superior - CAPES, por meio do Programa de PósGraduação em Ciências Tecnologias Ambientais da Universidade Federal do Sul da Bahia - UFSB.

Conflito de Interesses: declaramos que não há conflito de interesses. 


\section{Referências}

Almeida TM, Moreau AMSS, Moreau MS. 2008. Reorganização Socioeconômica no Extremo Sul da Bahia Decorrente da Introdução da Cultura do Eucalipto. Sociedade \& Natureza, 20(2):5-18. DOI: https://doi.org/10.1590/S198245132008000200001

Almeida RFB, Ferreira Júnior LG, Bayer M. 2018. Análise da cobertura e uso da terra da bacia hidrográfica do rio do coco e suas implicações sobre as áreas de preservação permanente como instrumento na gestão dos recursos hídricos. Desenvolvimento e Meio Ambiente, 49(1):60- 83. DOI: https://doi.org/10.5380/dma.v49i0.58652

Alves, WS; Morais, WA; Martins, AP; Aquino, DS; Pereira, MAB.; Saleh, BB. 2019. Análise do uso da terra, da cobertura vegetal e da morfometria da bacia do Ribeirão Douradinho, no sudoeste de Goiás, Brasil. Revista Brasileira de Geografia Física,12(3):1093-1113. DOI: https://doi.org/10.26848/rbgf.v12.3.p1093-1113

ANA. Agência Nacional de Águas. Hidroweb. Disponível em: <http://hidroweb.ana.gov.br/HidroWeb>. Acesso em: 10/03/2020

Azevedo DG, Gomes RL, Moraes MEB. 2016. Estudos da Fragmentação da Paisagem na Definição de Áreas Prioritárias Para a Recuperação Ambiental da Bacia Hidrográfica do Rio Buranhém. Boletim de Geografia, 34(2):127-144. DOI: https://doi.org/10.4025/bolgeogr.v34i2.25554

Brasil. 1997. Lei no 9.433 de 08 de janeiro de 1997. Diário Oficial da república Federativa do Brasil, Brasília, DF, 9 de jan. 1997. Disponível em: < http://www.planalto.gov.br/ccivil_03/leis/19433.htm>. Acesso em: 21/03/2020.

Brasil. 2012. Lei n ${ }^{\circ} 12.651$ de 25 de maio de 2012. Diário Oficial [da] república Federativa do Brasil, Brasília, DF, 25 de maio de 2012. Disponível em: < http://www.planalto.gov.br/ccivil_03/_ato2011-2014/2012/lei/112651.htm>. Acesso em: 21/03/2020.

Brasil. 2007. Lei no 11.445, de 05 de janeiro de 2007. Diário Oficial da república Federativa do Brasil, Brasília, DF, 5 de jan. 2007. Disponível em: < http://www.planalto.gov.br/ccivil_03/_ato2007-2010/2007/lei/111445.htm>. Acesso em: 21/03/2020

Cajazeiro JMD. 2012. Susceptibilidade a inundações nas bacias hidrográficas do Ribeirão Arrudas e do Ribeirão da Onça, Belo Horizonte - MG: análise comparativa por meio de índices morfométricos e taxa de impermeabilização. Dissertação (Mestrado em Pós Graduação Em Geografia) - Universidade Federal de Minas Gerais.

Chaves RR. 1999. Variabilidade da Precipitação na Região Sul do Nordeste e Sua Associação com Padrões Atmosféricos. Revista Brasileira de Geofísica, v.17(2-3):2010-232. DOI: http://dx.doi.org/10.1590/S0102-261X1999000200023

Christofoletti A. 1980. Geomorfologia, 2a edição, São Paulo: Editora Edgard Blucher, 188 p.

Costa MH, Botta A, Cardille JA. 2003. Effects of large-scale changes in land cover on the discharge of the Tocantins River, Southeastern Amazonia. Journal of Hydrology, 283 (1-4): 206- 217. DOI: https://doi.org/10.1016/S00221694(03)00267-1

Dutra GF, Timmers FJ, Mesquita CAB, Bedê LC, Pinheiro TC, Pinto LP. 2012. Biodiversidade e desenvolvimento na Bahia. Bahia análise de dados, 22(3):485-502.

EMBRAPA. Empresa Brasileira de Pesquisa Agropecuária. 2006. Centro Nacional de Pesquisa de Solos (Rio de Janeiro, RJ). Sistema brasileiro de classificação de solos. 2. ed. - Rio de Janeiro: EMBRAPA-SPI. 306 p.

IBGE. Instituto Brasileiro de Geografia e Estatística. 2017. Censo Agropecuário 2017 - Resultados preliminares. Disponível em: < https://cidades.ibge.gov.br> Acesso em 08/02/2019.

INDE. 2016. Infraestrutura Nacional de Dados Espaciais. Unidades de Planejamento Hídrico. Disponível em: <http:// www.metadados.inde.gov.br/geonetwork/srv/por/metadata.show?id=70952\&currTab=simple $>$. Acesso em 08/02/2020. 
INPE. Instituto Nacional de Pesquisas Espaciais. Banco de Dados Geomorfométricos do Brasil. TOPODATA. <http:// www.dsr.inpe.br/topodata/acesso.php>. Acesso: 15/06/2019.

Kabite G, Gessesse B. 2018. Hydro-geomorphological characterization of Dhidhessa River Basin, Ethiopia. International Soil and Water Conservation Research, 6(2):175-183. DOI: https://doi.org/10.1016/j.iswcr.2018.02.003

Lopes ERN, Souza JC, Sousa JAP, Albuquerque Filho JL, Lourenço RW. 2018. Modelagem Ambiental de Bacias Hidrográficas: Caracterização Morfométrica e Pedológica da Bacia do Rio Una - Ibiúna, Brasil. Revista Geosul, 33(66):105-127. DOI: https://doi.org/10.5007/2177-5230.2018v33n66p105

Lorenzon S, Fraga AS, Moreira AMR, Uliana ME, Silva DD, Ribeiro CAAS, Borges AC. 2015. Influência das características morfométricas da bacia hidrográfica do rio Benevente nas enchentes no município de Alfredo Chaves-ES. Ambiente \& Água, 10(1):195-206. DOI: http://dx.doi.org/10.4136/ambi-agua.1475

Mendonça JR, Carvalho AM, Matos LAS. 1994. 45 Anos de desmatamento no Sul da Bahia. Projeto Mata Atlântica do Nordeste. Ceplac, Ilhéus-Bahia.

Milani JR, Canali NE. 2000. Análise morfométrica do complexo hidrográfico do rio matinhos por uma análise morfométrica. Curitiba: Revista RA'EGA, 4(1):139-152. DOI: http://dx.doi.org/10.5380/raega.v4i0.3345

MMA. Ministério do Meio Ambiente. 2006. O corredor central da mata atlântica: uma nova escala de conservação da biodiversidade. Brasília: MMA; Conservação Internacional.

Mundetia N, Sharma D, Dubey SK. 2018. Morphometric assessment and sub-watershed prioritization of Khari River basin in semi-arid region of Rajasthan, India. Arabian Journal of Geosciences, 11(18):3-18. DOI: https://doi.org/10.1007/ s12517-018-3819-5

Oliveira ED, Oliveira ED, Crestani A. 2011. Caracterização fisiográfica da bacia de drenagem do córrego Jandaia, Jandaia do Sul/PR. ACTA Geográfica, 5(10):169-183. DOI: https://doi.org/10.5654/actageo2011.0510.0010

QGIS. 2016. QGIS Geographic Information System. Open Source Geospatial Foundation Project. Disponível em: $<$ http://www.qgis.org/>. Acesso em: 11/12/2018.

Ribeiro MC, Holvorcem CGD, Marques A, Martensen AC, Metzger JPW, Tambosi L. 2012. Monitoramento Independente da Cobertura Florestal das Bacias Setentrionais do Extremo Sul da Bahia. Dryad Digital Repository. Disponível em: < http://ibio.org.br/pb/projetos/monitoramento-da-cobertura-vegetal-no-sul-da-bahia-ba>. Acesso em: 15/12/2018.

Ribeiro MC, Santos JS, Ribeiro JW, Marques A, Borges R, Andrade D, Sette P, Leal S, Waldburger T, Novaes W, Andrade AC. 2015. Monitoramento independente da cobertura vegetal dos municípios da área de influência da Veracel no Extremo Sul da Bahia para o ano 2013. Relatório técnico BIO/ECONAMFI/LEEC/ECONECTA.

Rocha PC. 2010. Indicadores de alteração hidrológica no alto rio Paraná: intervenções humanas e implicações na dinâmica do ambiente fluvial. Sociedade \& Natureza, 22(1):191-211. DOI: http://dx.doi.org/10.1590/S1982-45132010000100014.

Santos EHM, Griebeler NP, Oliveira LFC. 2010. Relação entre uso do solo e comportamento hidrológico na bacia hidrográfica do Ribeirão João Leite. Revista Brasileira de Engenharia Agrícola e Ambiental, 14(8):826-834. DOI: http://dx.doi.org/10.1590/S1415-43662010000800006.

Sarkar D, Mondal P, Sutradhar S, Sarkar P. 2020. Morphometric Analysis Using SRTM-DEM and GIS of Nagar River Basin, Indo-Bangladesh Barind Tract. Journal of the Indian Society of Remote Sensing, 48(1): 597-614. DOI: https:// doi.org/10.1007/s12524-020-01106-7

Schumm SA. 1956. Evolution of drainage systems and slopes in badlands at Perth Amboy, New Jersey. Geological Society of America Bulletin, 67(5):597- 646. DOI: https://doi.org/10.1130/0016-7606(1956)67[597:EODSAS]2.0.CO;2

Schussel Z, Nascimento Neto P. 2015. Gestão Por Bacias Hidrográficas: Do Debate Teórico À Gestão Municipal. Ambiente \& Sociedade. 18(3):137-152. DOI: https://doi.org/10.1590/1809-4422ASOC838V1832015 
Sousa FA, Rodrigues SC. 2012. Aspectos morfométricos como subsídio ao estudo da condutividade hidráulica e suscetibilidade erosiva dos solos. Mercator - Revista de Geografia da UFC, 11(25):141-151. DOI: https://doi.org/10.4215/ RM2012.1125.0011

Strahler, A. N. 1964. Quantitative geomorphology of drainage basins and channel networks. Handbook of Applied Hydrology, edited by V. T. Chow, 4-39/4-76. New York: McGraw-Hill, 196p.

SEI. 2015. Superintendência de Estudos Econômicos e Sociais. Perfil dos Territórios de Identidade da Bahia. Salvador: SEI, 1(1): 233-260.

Thompson SK. 1992. Sampling. New York: Wiley-Interscience Publication. 343p.

Tucci CEM. 1993. Hidrologia - Ciência e Aplicação. Porto Alegre: Editora da Universidade, 1993. 943p.

Tucci CEM. 2002. Impactos da variabilidade climática e do uso do solo nos recursos hídricos. Câmara Temática sobre Recursos Hídricos, Fórum Brasileiro de Mudanças Climáticas. [S.l: s.n.].

Tucci CEM, Mendes CA. 2006. Avaliação ambiental integrada de bacia hidrográfica. Ministério do Meio Ambiente. Brasília: MMA. 302 p.

Villela SM, Mattos A. 1975. Hidrologia Aplicada. Editora Mc Graw Hill, São Paulo, 245p. 